\title{
Computer Modelling and Analysis of Polymer Composite Concrete Septic Tank
}

\author{
Raji .S .A ${ }^{1}$, Ako T. ${ }^{2}$, Ogbonna C. A. ${ }^{3}$, Popoola .O .H ${ }^{4}$ \\ ${ }^{1,2,3,4}$ Department of Civil Engineering, University of Ilorin P.M.B. 1515, Ilorin, Ilorin, Kwara state, Nigeria
}

\begin{abstract}
This study entails computer modelling of reprocessed pure water sachet (PWS) polymer composite concrete septic tank using MIDAS GEN engineering software. The project attempts to model a septic tank considering the properties of reprocessed pure water sachet polymer concrete such as modulus of elasticity, thermal coefficient, poisson ratio and damping ratio in order to determine its performance during service life. More than $45 \%$ of ultimate treatment can be accomplished in the septic tank. Based on review of past Laboratory research the compressive strength of reprocessed PWS determined after 7, 14, 21, 28 days of curing in water respectively was observed to increase as the curing days increased. The strength at $10 \%$ PWS of concrete increased from $17.60 \mathrm{~N} / \mathrm{mm}^{2}$ for 7 days curing age to $21.20 \mathrm{~N} / \mathrm{mm}^{2}$ for 28days curing age. The values of the stresses obtained increased with depth of the septic tank under the critical conditions considered. At depth of $1.5 \mathrm{~m}$, stress was established as $3.43 \mathrm{~N} / \mathrm{mm}^{2}, 4.32 \mathrm{~N} / \mathrm{mm}^{2} 4.85 \mathrm{~N} / \mathrm{mm}^{2}$ when the tank is empty, half-full and full respectively. The stresses obtained using the Midas engineering software was higher as compared with the manual computation.
\end{abstract}

Keywords: Reprocessed polyethylene water sachet, Polymer concrete, septic tank, computer modeling

\section{Introduction}

Currently more than one-third of the nation's wastewater treatment is provided by septic tank systems.

The septic tank is an enclosed receptacle designed to collect wastewater, segregate settleable and floatable solids (sludge and scum), accumulate, consolidate and store solids, digest organic matter and discharge treated effluent.

Concrete is a complex composite material, which begins its life as a mixture of graded stone aggregate particles suspended in a fluid of cement, water and sometimes admixtures. Nominally, aggregate occupies $75 \%$ of the volume, cement about $15 \%$ and water content $10 \%$. The priority when choosing a mix design is strength, which along with permeability of the concrete is governed by the watercement ratio. For high strength and low permeability the water-cement ratio should be low. This describes the ease of placing and compaction of concrete for a fixed water-cement ratio which is adjusted by choice of aggregate quantity, grading and shape, and also by the assistance of chemical plasticizers. Larger, rounded aggregate tends towards greater workability [1]

Polymer concrete which is a composite material is formed by the combination of mineral aggregate such as sand, gravel with monomers. Polymer-modified concrete (PMC) is the result of adding higher-molecular-weight polymers to concrete batch designs for the purposes of improved adhesion, greater chemical resistance, lower permeability, lower drying shrinkage, improved tensile strength, or accelerated cure. In this research work, reprocessed polyethylene pure water sachet "PWS" is considered as the composite material to be used with concrete. PWS popularly called "pure water" in Nigeria is a polymeric film material used in packaging portable water. PWS are made out of low density polyethylene (LDPE) or sometimes high density polyethylene (HDPE) by the extrusion of polyethylene resin which is then drawn into tubes sealable by the [2]. This reprocessed PWS is then added as monomer into concrete and it use is applicable in block work, concrete elements and also in hydraulic structures such as VIP toilets, drains, culverts, concrete pipes septic tank etc.

Thus, this study is aimed at analyzing and modelling a polymer composite concrete septic tank using MIDAS Engineering software and comparing the outcome with known benchmark results.

\section{Materials and Methods}

Materials: Polyethylene PWS, Organic solvent K, fine and coarse Aggregates, Cement, Water.

Polymer Pre-treatment: The processes of reprocessing the polyethylene PWS are stated as follows [2]

- Collection of pure water sachet PWS

- Washing with soap and water

- Drying

- The dried sachets were soaked in nitrocellulose thinner to remove the labels and other ink related matter on the used sachets and later re-dried.

- Shredding and re-blending with virgin polymer resin.

- Chemical treatment with organic solvent K

\section{Consideration of Laboratory Tests}

Sieve Analysis Test: Grain size analysis of samples is of paramount importance in selecting suitable type of soil use in construction. The test was carried out in accordance with ASTM D422 62 in order to select the grain size of sand and granite [3].

Compressive strength test: The compressive strength of each polymer cement concrete was tested using the $600 \mathrm{kN}$ Avery Denison universal testing machine and the result is presented in Table 1.

Table 1: Results of combine compressive strength $\left(\mathrm{N} / \mathrm{mm}^{2}\right)$ for $0 \%$ to $50 \%$ PWS 


\section{International Journal of Science and Research (IJSR) \\ ISSN (Online): 2319-7064}

Index Copernicus Value (2013): 6.14 | Impact Factor (2015): 6.391

\begin{tabular}{|c|c|c|c|c|c|c|}
\hline \%PWS & \multicolumn{6}{|c|}{ Compressive strength $\left(\mathrm{N} / \mathrm{mm}^{2}\right)$} \\
\hline $\begin{array}{l}\text { Curing } \\
\text { Days }\end{array}$ & 0 & 10 & 20 & 30 & 40 & 50 \\
\hline 7 & 18.35 & 17.60 & 12.96 & 8.78 & 8.40 & 6.69 \\
\hline 14 & 20.55 & 19.98 & 19.52 & 18.88 & 14.72 & 12.75 \\
\hline 21 & 21.30 & 20.50 & 20.00 & 12.94 & 12.40 & 11.59 \\
\hline 28 & 21.97 & 21.20 & 18.92 & 18.40 & 17.99 & 12.60 \\
\hline
\end{tabular}

Source: [3]

\section{Manual Calculations}

The following Procedures were used;

- Obtain standard dimension of septic tank according to BS 6297

- Consider design condition applied according to BS 8110\& BS 8007

- Design for roof slab

- Check for shear

- Check for stability when tank is empty (i.e overturning and wall collapse)

- Check for stability when tank is half full

- Check for stability when tank is full.

To determine the size of septic tank for an average 150 students residing in the hostel.

Total capacity $=180 \mathrm{~N}+2000$

$\mathrm{N}=$ number of persons

Internal dimension of $1^{\text {st }}$ chamber $=5.08 \mathrm{~m} \times 2.54 \mathrm{~m} \times 1.5 \mathrm{~m}$

Computer Modelling \& Analysis Method using MIDAS Engineering software.

Midas Gen is the package used for this study. Midas Gen is an integrated design system for building and general structures; it has it diversity in the analysis of stadiums, power plant, pressure vessels, machine structures, underground structures etc.

\section{Procedures}

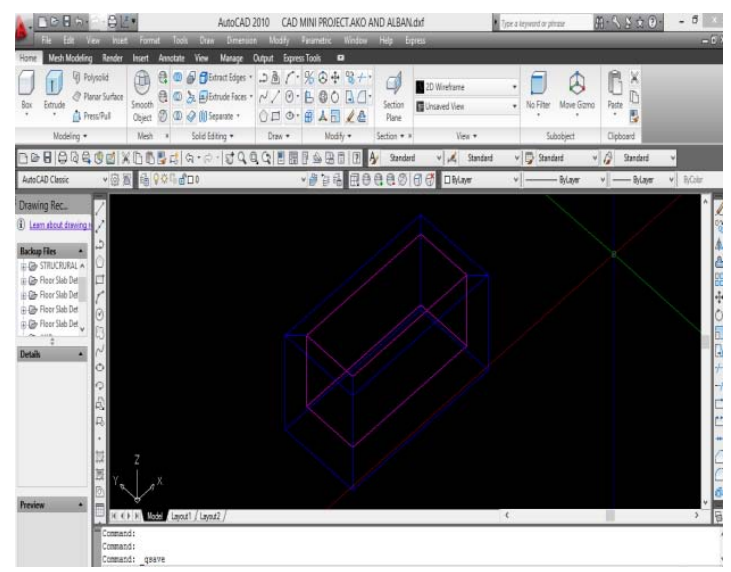

Figure 1.0: Creating a structural layered drawing Using AutoCAD

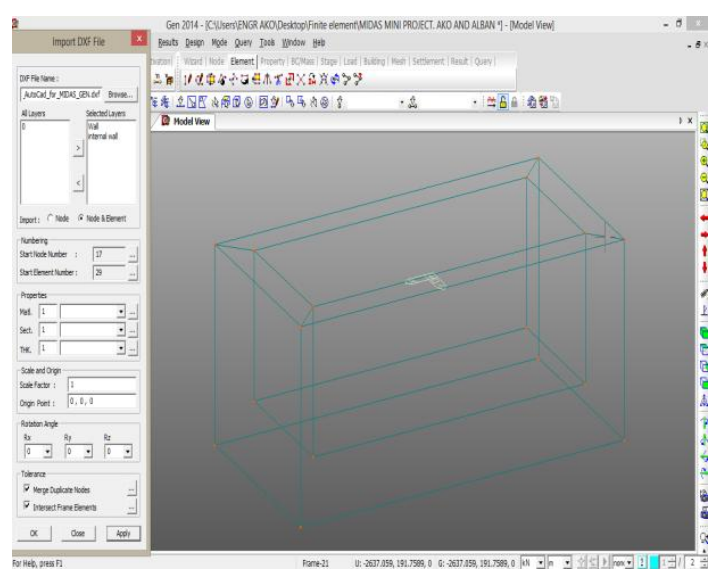

Figure 1.2: Importing AutoCAD to MIDAS GEN 2014

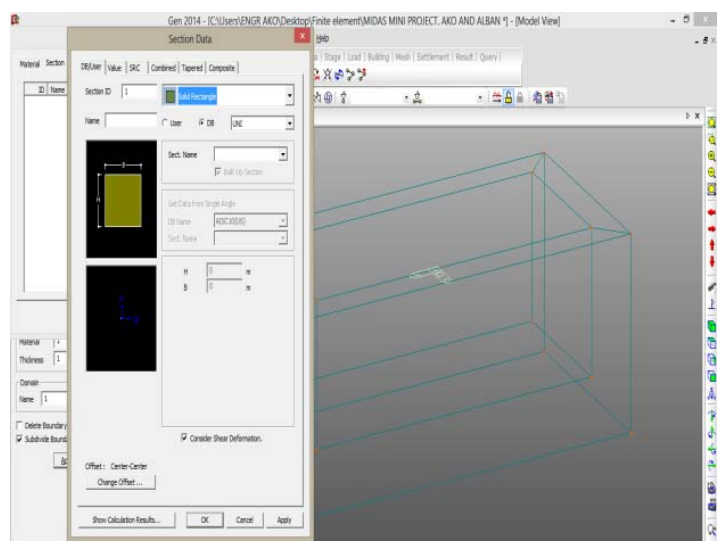

Figure 1.3: Defining of structural properties

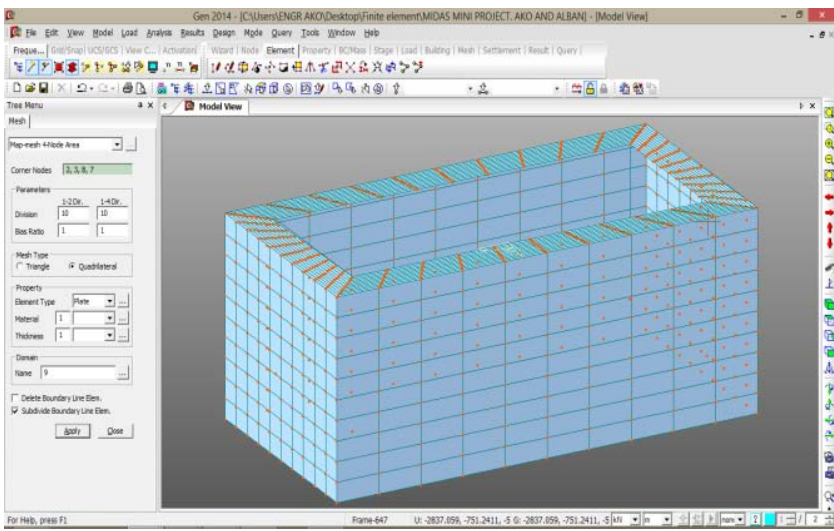

Figure 1.4: Meshing

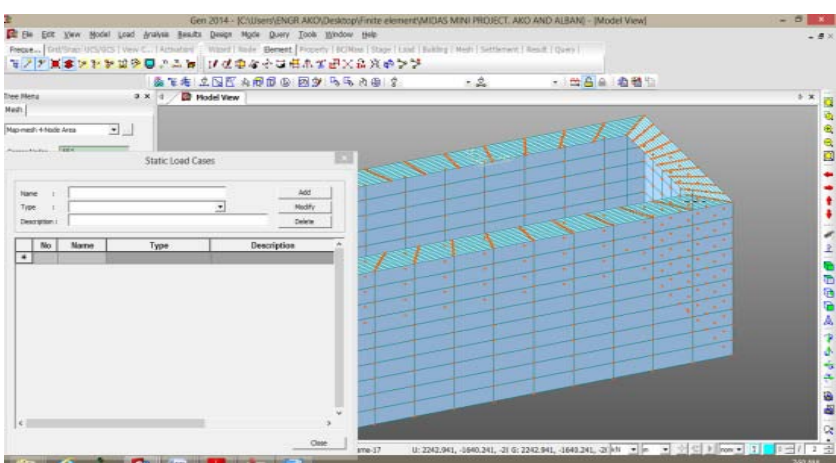

Figure 1.5: Defining of loads 


\section{International Journal of Science and Research (IJSR) \\ ISSN (Online): 2319-7064}

Index Copernicus Value (2013): 6.14 | Impact Factor (2015): 6.391

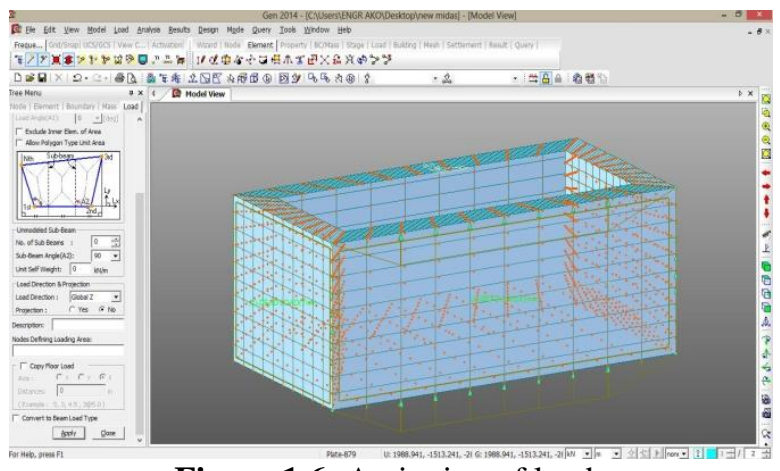

Figure 1.6: Assigning of loads

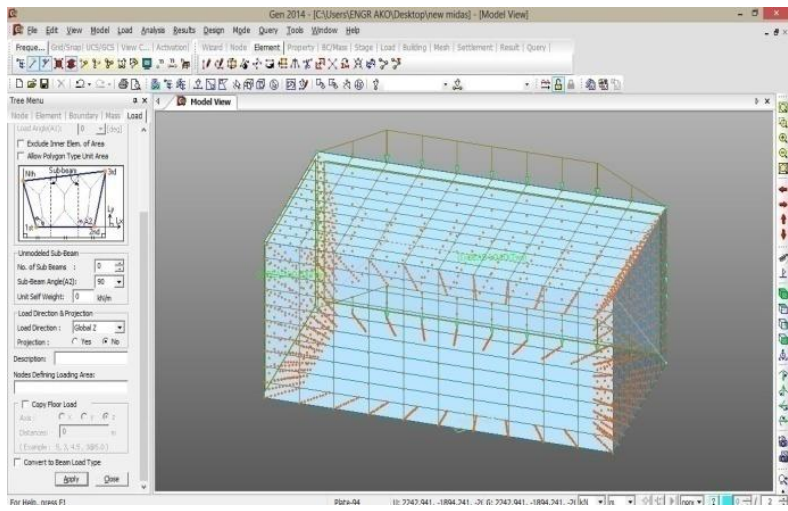

Figure 1.7: Run analysis

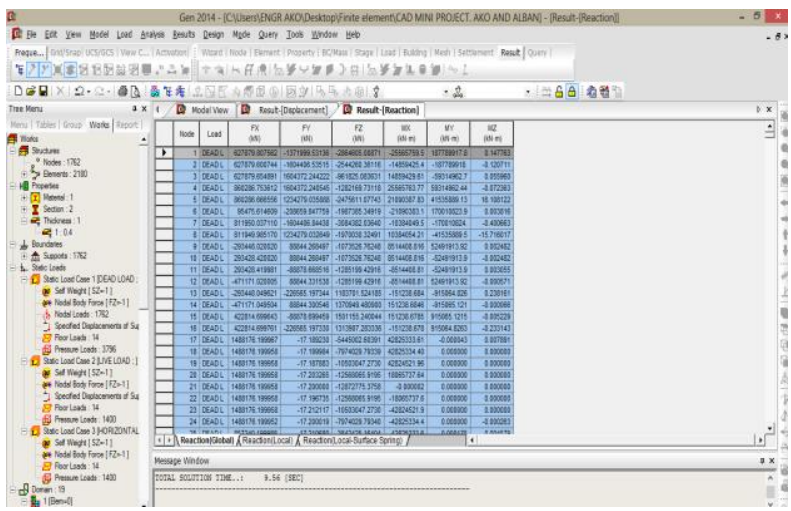

Figure 1.8: Display of results

\section{Results and Discussion}

Table 2 shows the Comparison between Manual Computation and Software Application.

Table 2: Comparison between Manual Computation and Software Application

\begin{tabular}{|c|c|c|c|c|}
\hline CONDITION & $\begin{array}{c}\text { Depth, z } \\
(\mathrm{m})\end{array}$ & $\begin{array}{c}\text { Manual } \\
\text { Computation } \\
\mathrm{N} / \mathrm{mm}^{2}\end{array}$ & $\begin{array}{c}\text { Software } \\
\text { Application } \\
\mathrm{N} / \mathrm{mm}^{2}\end{array}$ & Difference \\
\hline Empty & 0.75 & 2.69 & 4.99 & 2.30 \\
\hline & 1.50 & 3.43 & 5.23 & 1.80 \\
\hline Half-full & 0.75 & 3.58 & 5.42 & 1.84 \\
& 1.50 & 4.32 & 6.34 & 2.40 \\
\hline Full & 0.75 & 4.11 & 6.51 & 2.40 \\
& 1.50 & 4.85 & 7.43 & 2.58 \\
\hline
\end{tabular}

Results above showed that mass concrete was used for wall of septic tank instead of block work, this is because of the need to model the concrete material using polymer concrete. In the calculations, concrete wall thickness $=400 \mathrm{~mm}$, height of wall $=1500$, floor thickness $=500 \mathrm{~mm}$ and half of the section of the tank was considered in determining the stability of the tank. Also, the roof slab designed as one way spanning using $10 \mathrm{~mm}$ reinforcement. The stresses obtained at depth of $1.5 \mathrm{~m}$ considering different critical states is greater than that obtained at $0.75 \mathrm{~m}$ depth.

\section{Conclusions and Recommendations}

Based on review of past laboratory research the compressive strength of reprocessed PWS determined after 7, 14, 21, 28 days of curing in water respectively was observed to increase as the curing days increased. The strength at $10 \%$ PWS of concrete increased from $17.60 \mathrm{~N} / \mathrm{mm}^{2}$ for 7 days curing age to $21.20 \mathrm{~N} / \mathrm{mm}^{2}$ for 28days curing age.

Considering the critical conditions It can also be concluded that stress increased with depth where maximum stress is at depth of $1.5 \mathrm{~m}$. The values of the stresses obtained increased with depth of the septic tank under the critical conditions considered. At depth of $1.5 \mathrm{~m}$, stress was established as $3.43 \mathrm{~N} / \mathrm{mm}^{2}, 4.32 \mathrm{~N} / \mathrm{mm}^{2} 4.85 \mathrm{~N} / \mathrm{mm}^{2}$ when the tank is empty, half-full and full respectively. The stresses obtained using the Midas Engineering software was higher as compared with the manual computation. Thus, the steps involved in conventional design of structures which are undertaken manually are carried out much faster by the computer and with a reduced possibility of computational errors.

\section{References}

[1] Lawson, I., Danso, K.A., Odoi, H.C., Adjei, C.A., Quashie, F.K., Mumuni, I.I. and Ibrahim, I.S. (2011), "Non-Destructive Evaluation of Concrete using Ultrasonic Pulse Velocity", Research Journal of Applied Sciences, Engineering and Technology 3(6): 499-504, ISSN: 2040-7467

[2] Abdulkareem, S.A. and Garba, B. (2005). "Novel application of polymer dissolution technique". Nigerian Journal Pure and Applied science, Vol 20, Pp 1799-1803.

[3] Balogun, O.S.(2007). "Use of reprocessed "pure water sachet"(PWS) on hydraulic structures", An unpublished B.Eng. thesis submitted to Civil Engineering Department, University of Ilorin, Ilorin, Nigeria

[4] Islam, M.A. Rahman, M.M. and Ahmed, M.(2011), Polymer-modified Concrete: World Experience and Potential for Bangladesh, Indian Concrete Journal, pp. 55-63.

[5] American Concrete Institute (2003). "PolymerModified Concrete", ACI Committee report ACI 548.3R-03. pp 1-47.

[6] Bhutta, A.M and Ohama, Y. (2010). "Recent Status of Research and Development of Concrete-Polymer Composites in Japan". Concrete research letter, vol 1(4), pp 125-130. 